\title{
Universities as Laboratories. Internationalisation and the Liquidity of National Learning
}

\author{
Stefano Bianchini
}

\begin{abstract}
This chapter explores circumstances and opportunities that mark the internationalisation of European Universities after the Cold War. It reports the results achieved by the European human capital strategy with a specific focus on the Erasmus mobility impact on young generations. It expands the analysis to transnational research and networks as modern methods of work for academic investigation. Then, the article highlights some crucial aspects of the debate on the social role of Higher Institutions, how disciplines should complement education, and University potentials implemented in support of their social engagement. Particular relevance is given to the internationalisation of Higher Education Institutions in years characterized by globalisation. By affecting national policies of education and research, its inputs contribute, in fact, to melt the homogenisation of cultures and languages promoted in the last two centuries. By contrast, this process generates tough resistances, which threaten the transnational education under construction. Subsequently, it is widening the gap between mobile and sedentary educated people. This may produce social conflicts with unpredictable impacts on how knowledge should be constructed, with the risk of stifling the role of Universities as laboratories of universal culture.
\end{abstract}

\section{Keywords}

internationalisation of education - Erasmus Programmes - mobility - transnational education

The end of the Cold War gave new impetus to the idea of the university in Europe. By bulldozing the Iron Curtain, existing ideological and geographical borders were swept away. In this context, the universities, whose very word 
echoes with the 'universal' insight of science, erudition, and learning, had a tremendous opportunity to capture this momentum and invigorate their mission by promoting a new international dimension for their curricula, a scholarly cross-national networking, and a regular exchange of research outcomes and achievements.

Qualitatively and radically, this opportunity materialised with the progress of EU integration, its widening and deepening between 1992 and 2004. Diachronically, the extremes of this period go from the Maastricht Treaty (which established both the EU common currency and European citizenship) to the zenith of the integration process, well represented by the great enlargement eastward and the signing of the Constitutional treaty.

It is within this critical period of European strategic transformations that the EU member states convened on the need to give universities a 'great leap forward' in internationalisation by creating compatible diplomas, standards, and quality levels of education not only through a harmonisation of the architecture of higher educational institutions among the member states but also and vitally important - through new forms of university interactions.

The Bologna process, which began in 1999, embodied this transnational effort. Not without discrepancies and harsh criticisms aimed at the increasing amount of bureaucracy, this process has radically transformed university structures and their teaching contents Europe-wide. A remarkable crossnational fertilisation has marked the EU (with limited results only in the United Kingdom), including most of its neighbouring countries, the Russian Federation, and, gradually, Central Asia. As a result, a European Higher Educational Area (EHEA) was established. By December 2015, it had encompassed 49 countries, far beyond the number of EU member states (and candidate or potential candidate countries), which is a confirmation that the advancement of research and knowledge increasingly depends on cooperation and exchanges across borders.

Basically, the implementation of such an ambitious design was structured according to a set of measures, among these:

- a three-cycle system of studies;

- mutually recognised and comparable degrees;

- scholarships for student mobility;

- teaching and research programmes aimed to encourage professor and staff mobility;

- a framework for joint programmes and new degrees, whose format can be based on joint, double, or multiple diplomas, implying different levels of mobility in all the subjects involved; and

- financial support for transnational networks for joint research projects. 
The result is transnational educational and research partnerships that are key investments for building that European human capital, which will be fit to compete at the global level.

\section{Building a European Human Capital: Some Data}

Recent statistics issued by the European Commission in July 2014 offer a clear picture of the results achieved so far as a result of student mobility in Europe: the Erasmus Programme. Remarkably, 3 million students have enjoyed this programme since it was established in $1987-1988$, and this interuniversity practice is intensifying. A recent study has recorded that, during one academic year alone, 2012-2013, 268,143 students went to another EU country for study or training. Of these, $61 \%$ were women, $67 \%$ were enrolled at the BA level, and $29 \%$ at the MA level. Of all students involved in the Erasmus Programme during the academic year 2012-2013, 79\% took advantage of this opportunity to attend courses and pass exams, while $21 \%$ received a grant for a job placement in companies in another EU member state. Looking toward the future, EU investments in the new Erasmus plus Programme for the years 2014-2020 have been designed to award grants up to another 2 million higher education students. ${ }^{1}$

In consideration of these numbers and with the aim of measuring the impact of this programme on students' attitudes towards the process of European integration, the European Commission committed the 'Generation Europe Foundation' to carrying out a specific project, called EVA (Erasmus Voting Assessment), whose task was to investigate (1) the extent to which the Erasmus Programme has an impact on the EU feelings of the young generations involved in the Programme and (2) whether these feelings were also translated into voting behaviour. A very interesting report was published in July 2014 by the aforementioned Foundation, in cooperation with AEGEE and the International Exchange Erasmus Students' Network with two introductory remarks by the Commissioner Androulla Vassiliou and the EP member Doris Pack.

According to the survey results, collected and elaborated by the EVA research before the EP elections of 2014, 91\% of respondents (aged 18-25) admitted to thinking of themselves as European citizens, and not just as a national of an EU member state, 'often ( $45 \%)$ or sometimes (46\%)'. Compared with the Eurobarometer data of 2007 (which surveyed a young generation aged 15-24), the sense of closeness to European identity shown by university students was

1 http://europa.eu/rapid/press-release_IP-14-821_en.htm. 
steadfastly greater. In the Eurobarometer answers, in fact, only $54 \%$ of respondents think of themselves as European citizens often or sometimes.

Even more interesting is the difference in opinions that emerged between mobile and non-mobile students when requested to express what the EU meant for them. All 'positive' meanings related to the EU context were more appreciated by current or former Erasmus students than those who never studied in another country. In other words, a large majority was more likely to associate the idea of Europe with the ability to move within and across the borders of the member states; with the guarantee of a better future; with the protection of the rights of citizens, of peace, and a lasting economic situation; with the development of job opportunities; and even with the establishment of a European government.

It is worth stressing that particularly those aspects, which can be defined as 'political by nature', manifested the greatest distance in percentage between mobile and non-mobile students. As a result, the identification of the EU with lasting peace was appreciated by $40 \%$ of the former versus $29 \%$ of the latter. Similarly, the protection of citizens' rights attracted the support of $45 \%$ of the former versus $37 \%$ of the latter. Improvement in the EU's economic future was deeply rooted in the beliefs of the $41 \%$ of the mobile students versus $37 \%$ of non-mobile, and even the perspective of EU government involved identifying with the meaning of the EU by $34 \%$ of the mobile students versus $30 \%$ of the non-mobile. By contrast, a tiny percentage (between 10\%-13\%) of non-mobile students rather than those mobile (between $8 \%$ and $10 \%$ ) was concerned about the risk of losing national identity and the influence of greater EU bureaucracy or expressed their Euroscepticism by believing that the EU was just a utopian project'. Furthermore, the feeling of EvA respondents about the future of the European Union was $73 \%$ optimistic and only $13 \%$ pessimistic. Considering the long-lasting impact of the EU crisis, which politically dates back to 2005 when the Constitutional treaty was rejected, and was later economically worsened because of the financial and sovereign debt crisis that began in 2008, this answer may sound quite surprising. And, in fact, EVA respondents showed a clear belief in the future of the EU, definitely more persuaded than the European population in general, whose optimism was contained to the $53 \%$ versus the $40 \%$ of pessimists, as the Eurobarometer recorded in 2014.

Even more interesting is the fact that the optimism of mobile students does not cast a shadow over their concerns - which still exist - about negative scenarios, mainly related to the risk of the deepening of the economic and financial crisis, social uncertainties, and the impact of future accessions.

In the end, the EvA research provided evidence about the level of information that mobile and non-mobile students have about EU institutions and the 
forthcoming EU parliamentary elections. Once again, the survey clarifies that current and past Erasmus students share a better knowledge of the mechanisms of the EP elections, the EU institutional framework, and how it works. Approximately $70 \%$ of them know that MEPs are elected in direct general elections by the European population. Although it might be surprising that $30 \%$ still believe that they are not elected by citizens, the percentage of $70 \%$ is significantly higher than the $50 \%$ recorded by the Eurobarometer in 2013 for young people of similar age (18-30). Significantly enough, $81 \%$ of students who in their past made use of an Erasmus mobility period voted in the EP elections in 2014: by contrast, the vote of those who were never abroad involved $7 \%$ fewer people, namely $74 \%$ of students.

It should also be noted that turnout in the EP elections in 2014 was $42.54 \%$, while only $41 \%$ of the EVA-responding students who were using their mobility when the EP elections took place were likely to vote. In this case, however, the responsibility of the member states, the complexity of regulations, and/or a lack of support played a crucial role in obstructing the vote of young people during the period of mobility: as a result, $43 \%$ of the respondents who did not vote complained about the difficulties they had to face in order to be registered to vote, while $30 \%$ declared that they lacked the money to travel back to their polling station at home. Lack of information or commitment reached a much lower percentage, around $10 \%$ or even less.

To conclude, the EVA report stressed how respondents revealed 'a closer sense of identification with the EU, had a more positive outlook on its future, were more interested in participating, and indeed were more likely to vote during the European elections.' ${ }^{2}$ In a sense, these figures also offer a transformative picture of the impact that a transnational, nomadic programme offered to students enrolled in the EU, like Erasmus, has on their behaviour, while they are still studying (Braidotti, 2011).

It is, however, interesting to note that this approach (and the mindset that stems from it) does not show a transitory character; on the contrary, it is likely to be confirmed once students approach the labour market. Recent available data state, in fact, that 5 years after graduation, unemployment among students who enjoyed an Erasmus grant was $23 \%$ lower than was the case of non-mobile students. The findings of broad-based research published in September 2014 under the title The Erasmus Impact Study not only confirmed the effectiveness of the programme in terms of employment opportunities but

2 Erasmus voting Assessment Project Final Report, Generation Europe Foundation: 2014, available at http://issuu.com/generationeurope/docs/evaproject_final_report_fordistribu/1 $? \mathrm{e}=1430744 / 9429338$, p. 35 . 
also provided crucial insights about the transversal competences that students acquire during their international experience: in particular, how deeply this experience marks their personality traits and attitudes in terms of tolerance, curiosity, adaptability, self-confidence, serenity, decisiveness in making decisions, and vigour in solving problems. In short, Erasmus vividly contributes to making young people more attracted by and more able to interact with a globalising world. ${ }^{3}$

This study was carried out for the European Commission by the Berlin CHE Consult (Centrum für Hochschulentwicklung) in partnership with the Brussels Education Services, the Compostela Group of Universities, and the Erasmus Student Network. Impressively, it surveyed nearly 79,00o mobile and nonmobile students, alumni, academic and non-academic staff, employers, and higher education institutions. The investigation stressed, among other things, that $93 \%$ of mobile students easily imagine their own future in another EU country (the percentage is $20 \%$ higher than that of non-mobile students) and $95 \%$ wish to work in international environments (versus $78 \%$ of non-mobile students). The nomadic inclination of Erasmus students is, in a sense, confirmed by the behaviour of alumni: $40 \%$ of them had changed country at least once after graduation, while only $22 \%$ of non-mobile students had.

Exploring the expectations and requirements of employers/entrepreneurs, the study emphasised that $92 \%$ of employers were looking for workers with the aforementioned transversal skills, well in addition to top knowledge in their field, when recruiting personnel. Furthermore, $64 \%$ of the employers noted in 2014 (versus $51 \%$ in 2006) how deeply the international background of graduates increased their own professional responsibility. Leadership as well is likely to emerge more effectively among Erasmus alumni: according to the data collected, $77 \%$ of them held positions with leadership components 10 years after graduation and $44 \%$ were more likely to be working as managers than non-mobile students.

Last, but not least, 'international love' has also played a relevant role in modifying lifestyles and behaviours in the EU context during, or because of, the Erasmus experience: in particular, the study noted an intensification of mixed couples, with $33 \%$ of alumni living with a partner of a different citizenship/nationality, while this percentage was much lower (13\%) in the case of non-mobility students. In addition, $27 \%$ of Erasmus alumni declared they had met their current partner during their mobility period, and it has also

3 Erasmus Impact Study - Effects of mobility on the skills and employability of students and the internationalisation of higher education institutions, available at http://www.eubusiness.com/topics/education/erasmus-impact, European Commission: Brussels, 22 Sept. 2014. 
been calculated that approximately one million babies were born under these circumstances.

\section{Globalisation and the Underestimation of European University Internationalisation}

Despite the broad and stimulating research conducted on students and alumni actively involved in mobility in the past few years, the study of the Erasmus impact on the academic and administrative staff of universities is regrettably less systematic and, to a large extent, poorer in terms of data and figures. Indeed, scrutiny needs to be expanded to broader dimensions in order to take in the impact of globalisation on the organisation of knowledge, how that knowledge is being disseminated, and to what extent it is receptive to the time-space compression that globalisation is intensifying (Szyszlo, 2016).

From this perspective, Erasmus mobility is just one component, although a crucially important one. University internationalisation, however, encompasses many activities, which include mobility of students, professors and staff, transnational curricula adaptations, joint research projects, joint teaching programme design and transnational (double, multiple, joint) degrees awarding, which have an obvious impact on the learning processes at home.

Furthermore, internationalisation as such has been widely discussed in academia, where a diverse terminology has emerged when referring to this process. Authors like Hans De Wit (2013, pp. 14-18) or Jane Knight (2008, pp. 19-22) have repeatedly emphasised a diachronic development of terms that focus primarily on one specific aspect of internationalisation, for instance, mobility or curricula-related ones - that is, from peace studies to global and international studies, from multiculturalism to intercultural education - or on national programmes in English for native students (particularly in economics).

Furthermore, in reconstructing the internationalisation dynamics, De Wit (2013, p. 22) stressed how deeply forms and accents have varied vis-à-vis historical periods and countries. In particular, he emphasised the focus on aid and cooperation for development that was promoted between the 1970s and the 1980 s. Actually, this process began earlier - in the middle of the 1960 s already in the socialist countries that De Wit did not consider. Yugoslav and Soviet universities competed actively at the international level to attract the best students from the so-called 'Third World' by offering a wide spectrum of disciplines for their further education as a lever for promoting their own social systems worldwide. The Lumumba University in Moscow as well as the University of Belgrade (thanks to the Yugoslav non-alignment policy) were particularly 
active in this regard, and generations of African and Asian youngsters attended courses and learned the language before returning to their homelands.

True, most of the students of the Lumumba University in Moscow concentrated on their studies, remaining to a large extent isolated from the Soviet social context, but this was not the case in Yugoslavia, where the interaction with the local environment was much more dynamic and had a positive impact, even in terms of spreading knowledge of the Serbo-Croatian language internationally. It was not rare to meet alumni in China, the USA, or Libya, who were educated in Yugoslavia. Regrettably, the fall of communism and the violent dismemberment of Yugoslavia might be among the reasons why Western scholars have tended to downplay the relevance of this policy of international education that the socialist world had developed. Nevertheless, this experience explains to a large extent the background of interest and sensitivity of post-communist societies when it comes to raising their level of integration and internationalisation, as soon as the EU began to promote this policy.

This prospect began to mature, in reality, at the end of the 1980 s when the European community moved to scholarship programme compatibilities and promoted the first mobility schemes. Drawing inspiration from an essay by Stefan Zweig (2014), who had suggested already in 1932 allowing students to spend one semester, or even a year, in a university abroad in order to know the contribution of other peoples to the innovation of techniques and the shared history of European civilisation (by combining - interestingly enough - the studies of humanities with the hard sciences), the Erasmus Programme was launched, giving a new perspective to the internationalisation of universities.

So, Zweig's dream began to be realised thanks to the recognition of the exams passed in another European university as part of the curriculum established at the home university. The issue quickly attracted the interest of scholars, and, particularly with the new millennium, the literature widely debated the role of globalisation on educational systems: Uwe Brandenburg and De Wit (2011); Felix Maringa and Nick Foskett (2010); Philip Altbach, Lis Reisberg and Laura Rumbley (2009); Peter Scott (2005); Ulrich Teichler (2004), and other scholars have extensively analysed academic competition at the global level. They have highlighted the increasing relevance of the Asian universities, in contexts previously dominated by the Anglo-American and Australian educational systems, and noted the multiplication of international ranking systems of universities, which has encouraged either a shifting of university commitments in terms of cross-border and offshore education, or emphasised powerful trends aimed at supporting tradable commodities, while meantime eroding the perception of education as a public good. 
Curiously enough, however, all these studies have undermined the impact of internationalisation strategies on the process of EU integration. EU integration is definitely part and parcel of globalisation: therefore, its developments require filtering and contextualising in relation to the radical social and economic transformations that are challenging the primacy of USA education and its economy, thus granting a leading role to newly emerging countries as well, particularly the BRICs countries (Brazil, Russia, India, China, South Africa). Nevertheless, the Bologna process has a twofold goal: on the one hand, it aims to enhance the quality of education in order to compete globally; on the other, it aims to establish a European educational system beyond the member states dimension, since this effort is a crucial prerequisite for achieving the former. Successful steps in this direction have been taken already by involving the EHEA - as already noted - and a broader number of countries, from the Russian Federation to the Caucasus and Central Asia. Regrettably, this European dimension of the internationalisation of the universities is still underestimated in most of the international publications on the subject. There is no denying that the main reason for this appearance can be identified with the predominant role played by the Anglo-American educational system (their universities powerfully lead all international rankings), which remarkably influence the mental processing involved in the matter. Still, even the persistence in Europe of a nation-state political culture contributes to affecting - among other things the study and the assessment of the Europeanisation of education.

Hans De Wit, in his stimulating edited report of 2013, recognised the transformative role of the Erasmus Programme, which started working in 1987-1988 when 3244 students took advantage of it and the EU member states were just 12. Furthermore, he concluded that, 25 years later in 2013, Erasmus had not only forged an 'Erasmus generation' of 3 million students in the meantime but had also significantly contributed to the reform of higher education in Europe, the introduction of the EстS system, the development of the Bologna process, the implementation of inclusive policies towards East-Central European countries, and their prospective EU membership (carried out since 2004 and still under negotiation at least in South-Eastern Europe).

It should also be noted that over $5^{2,600}$ academic scholars and university staff took advantage of this programme by visiting and monitoring other European universities in the academic year 2012-2013, offering additional seminars or lectures during their stay at the $\mathrm{BA}, \mathrm{MA}$, or $\mathrm{PhD}$ levels. EU figures also state that 500 practitioners, namely staff members from business environments, were invited to teach under the aegis of the opportunities offered by the programme, with a $20 \%$ increase in participation in comparison with the previous year, and a consistent improvement in learning outcomes in terms of 
the practical knowledge of students as well as their theoretical and academic education.

Consequently, the European Commission decided to expand the Erasmus Programme (renamed 'Erasmus plus') both financially and in terms of scope and targets for the period 2014-2020. Once again, some data would help here. In 2007-2013 the available budget was 3.1 billion euro. For the years 2014-2020 the budget was increased up to 15 billion euros, with the ambitious aim of supporting the mobility of $20 \%$ of the student population, namely an additional 5 million people. Meanwhile, the member states are now $28,{ }^{4}$ and the programme is also open to students from Turkey, Iceland, Norway, Lichtenstein, and Switzerland.

All that considered, De Wit concluded that the new 'Erasmus plus' project with its stimuli for student mobility, together with the implementation of the internationalisation strategies of the higher education in Europe - 'is not a goal in itself but a means to enhance the quality of the educational experience and the international learning outcomes of the students. ${ }^{5}$

Admittedly, however, such an assessment still sounds reticent, since it is powerless to highlight the political implications of the process of the internationalisation of the universities in the framework of the European integration. As said, this is in reality the most underestimated aspect in the current literature, which focuses on globalisation and its effects but lacks any investigation into how transnational higher education and culture contribute to building new political relations in Europe and radically change the social environment of European societies.

Indeed, student mobility is a key component of the EU internationalisation strategy of the universities, since it corresponds to a remarkable investment policy in human capital through younger generations. Nevertheless, a more comprehensive analysis of EU efforts in promoting this internationalisation is needed, since a new - and politically vital - role is going to be played by the universities as a decisive lever for the further integration of Europe.

Looking from the perspective of internationalisation strategies, university life in Europe has radically changed in the last two decades.

4 Actually, they will drop to 27 when Brexit is finally implemented.

5 Hans De Wit (ed.), An Introduction to the Higher Education Internationalisation, Milan: Vita e Pensiero, 2013, p. 20. 
Thanks to students, professors, and staff mobility, cross-border and transnational knowledge have increasingly marked both the broader understanding of the reality and the designing of the curricula, with a transformative impact particularly in the humanities and social sciences, which crucially forge a sense of citizenship. True, the flourishing of technologies, the progress in new discoveries in medicine, and research in the natural and applied sciences in general are quite used to easily crossing borders and acquiring new data and stimuli by expanding exchanges and cooperation. Scientists normally work in (international) teams, operate in highly competitive contexts, and the transfer of discoveries has rapid social effects in everyday life. Yet, it is also true that the cultural and social sciences are developing in a different environment, which - by contrast - suffers, to a large extent, from containments imposed by nation-state narratives.

We have mentioned that universities encompass, in the very name 'university,' the idea of the universality of knowledge. Nevertheless, most of the higher educational institutions were established in Europe after 180o, that is, when industrialisation and the national form of the state were affecting social developments in Europe. Educational policies, learning outcomes, and teaching methodologies were consistently adjusted. In fact, while 118 universities were established in Europe over seven centuries, between 1088 (University of Bologna's foundation) and the French Revolution, between 1800 and 1940 alone another 119 universities began their programmes and nearly 6oo were founded after wwII. In other words, mass higher education has grown synchronically with industrialisation and the radical social transformations stemming from the increasing participation of the population at large in public affairs (in the sense of res publica) within the nation-state building process. Therefore, research and teaching activities have been primarily marked by a dual goal: on the one hand, to empower students with technical knowledge in order to prepare them for the world of work with solid competences, even by gradually transforming the universities into effective entrepreneurial players in support of the socioeconomic development of society. On the other hand, however, the universities have become a vector for a predominant interest in fostering the cultural $n a$ tional dimension through the study of national literatures, national histories, national histories of arts, national political and social sciences, etc. Lectures were held in national languages only (with rare exceptions), very few students attended courses in other countries (also because there were no-mechanisms of recognition), and the mobility of scholars was limited to some international events (conferences, seminars). As a result, knowledge was organised in such a way that recognition of the nation-state's solidification was presented as the final development of human society or, in short, the 'end of history'. 
By contrast, all these aspects, in one way or another, have been challenged by the EU after the fall of the Berlin wall. Once the Iron Curtain came crashing down, the Schengen treaty was put into force, the perception of borders rapidly vanished, and the process of universities' internationalisation accelerated by including mobility policies, the Bologna process, the introduction of the three-cycles system, the compatibility of diplomas, the transformation of teaching methodologies, the growing relevance of transversal skills, long-life learning, job placement, the diversification of diplomas together with the encouraging carrying out joint programmes with joint, double, multiple degrees.

During the 1990s, radical transformations affected the higher educational system, and alternative suggestions were elaborated particularly in terms of methodological approaches. The vexed question of the relationship between the social sciences and the humanities, on the one hand, and the exact and applied sciences, on the other, quickly revived. In the United States, especially at Stanford, the 'Triple Helix Concept' was elaborated in order to give priority to a narrow link of universities, enterprises, and public administrations. The idea of an entrepreneurial university to serve the needs of industries, officials, and decision-makers was actively explained in terms of international competitiveness requirements, thereby leaving the social sciences and the humanities on the margins of the educational system, while the management of universities was understood to be restructured as a business, (Etkowitz 1993; Etkowitz \& Leydesdorff, 1995; Ranga \& Etkowits, 2013).

Meantime, the development of new communication systems and IT encouraged UNESCO (2005) to issue a report where a broader 'knowledge society' was envisaged by critically raising questions about both the 'hegemony of the techno-scientific model' in producing knowledge and the obstacles, at the local and global level, that mark the participation of a society in the broader global information society. A whole chapter was devoted to the role of institutions of higher education. In particular, serious concerns were expressed about the future of European universities, due to the huge expansion in attendance (massification of studies) and the decline in public founding. The latter resulted in an attempt to diversify the financial resources through a 'marketisation and commercialisation of educational services' to the detriment of the research dimension. In reaction, the report suggested considering the option of developing transnational university networks. Under these conditions, as was suggested, both research and teaching functions would be preserved. Moreover, connecting the universities through a variety of transnational disciplinary networks would avoid the risk of reducing institutions of higher education to a mere third level of the school system. 
Even more stimulating was another UNESCO report (1996), which was revisited in 2013, and whose title was 'Learning: The Treasure Within'. Despite some criticism coming from the World Bank, the OECD, or some scholars like Bhola (1997), who were contented with a vision of education as 'profoundly humanistic... and less market driven', the Jacques Delors Commission (which wrote the document) introduced the lifelong-learning approach, by inviting both to rethink the challenges coming from information technologies and to develop learning approaches capable of respecting diversity. In particular, Delors suggested four main pillars for a more effective educational method. These pillars were articulated as follows: learning to know, learning to do, learning to be, and learning to live together. They offered an excellent reference framework, particularly for the internationalisation of the university programmes and joint/double/multiple degrees. Their combination, in reality, stimulates the exchange of knowledge at different levels, strengthens the link between research and teaching, as well as students' acquisition of what are known as 'transversal skills', including a greater independence and judgment due to the diversification of the learning experience through the mobility and the understanding of the variety of mindsets, histories, habits, and spirituality.

The Delors Report outlined a pioneering and very modern 'humanistic and integrated vision' of the learning process. However, when the Report was published in 1996, the neoliberal economic and utilitarian relationship between universities and business interests was the predominant (ideological) model, and the separation of disciplines was pursued with tenacity. Looking toward the future, however, this learning idea is doomed to lose its effectiveness, offering new room for the development of interdisciplinarity, and encouraging bridges between social sciences, humanities, and hard sciences.

Globalisation and interdependence, in reality, are already pushing in this direction: the recent success in fighting the Ebola virus epidemic in Africa blatantly showed that the medical search for a vaccine would not have eradicated the disease without the crucial support of anthropology, that is the ability (knowledge) to interact with the local mindset and beliefs.

As an additional confirmation, a recent article published in the online edition of Nature, with the forthright title 'Time for Social Sciences', clearly states that 'Governments that want the natural sciences to deliver more for society need to show greater commitment towards the social sciences and humanities. ${ }^{6}$ The key argument developed in the article refers exactly to the inclusion of social,

6 http://www.nature.com/news/time-for-the-social-sciences-1.16621?WT.ec_id=NATURE -20141225 . 
economic, and cultural factors in the physical, chemical, medical, biological, and environmental research features, otherwise 'a great deal of cultural creativity will be wasted'. Severely critical of the government of the United Kingdom for lacking any understanding of this commitment, the article stresses the relevance of inclusivity in the research of the natural sciences if their goal is to produce knowledge not only for the benefit of the society but also for the development of a 'capacity of understanding' the society (as well as to be understood by) in order to make the society receptive to innovations and able to accept and use them.

As the historian of economics Alexander Gerschenkron (1962) emphasised in the early 1960 in his seminal comparative study on the prerequisites for the economic take-off, a cultural predisposition in support of development and change is an unquestionable and decisive factor for success. Interdisciplinarity is, therefore, an additional, crucial component for the internationalisation of the universities and the transnational qualification of their programmes.

Consequently, how to achieve this qualification methodologically and improve human capital so as to be able to face the challenges of the increasing complexity and interdependence of our societies depends to a large extent on the ability to work in teams and operate through networks. Furthermore, the data included in the reports of the European Commission that were illustrated at the beginning of this chapter highlight very well how this is already furthering the construction of a transnational and networking-based human capital.

Networking and Post Nation-State Perspectives. Opportunities and Reserve

In this context, marked by interdependence and globalisation, networking is a crucial lever of change. Networking is a method of working, a scheme to make transnational cooperation and interdisciplinarity a habit for the scholarly world. Admittedly, not everybody in academia welcomes this approach, which is highly demanding, as it requires flexibility and a fluent multilingual attitude in order to teach, communicate at the scientific level, write projects and reports, publish, and be evaluated. Moreover, administrative mentalities either in the various ministries or in the universities often fear loss of control over the implementation of programmes and research activities, are therefore reluctant to apply flexible rules when, by contrast, they are crucially relevant for the smooth functioning of international cooperation. Still, networking has been increasingly embraced by a large part of the academic world, including the 
humanities and social sciences, which traditionally are disciplinary spheres more used to working individually.

Networking, in fact, has been vitally stimulated by the call for applications by the European Commission for scholars, students, and staff. In order to stimulate cross-national fertilisation, the proposals for research projects as well as educational, training, life-long programmes, opportunities for placement, etc., are to be structured on the basis of transnational teams and multiple partnerships when inviting submissions for financing. This requirement is not just a façade, since implementation of the projects has to be conceived starting with the applications and, then, carried out by strictly following a rationale based on active transnational forms of cooperation. Consequently, in order to make the networks work, the mobility of participants with different background and discipline approaches becomes inevitable. As a result, transnational networks, interdisciplinarity, and mobility are integrated as crucial factors that enable Europeans to meet and share institutions, economic interests, a legal framework, habits, ways of conducts, behaviours, cultures, and friendship.

Networking also provides a vital opportunity to encourage scholars and students to cope with a plurality of angles and to look at the world through a variety of lenses. Alternative narratives have therefore identified unexpected room for matching: the public discussions that followed have paved the way either to 'discover' the métis nature of European cultures or to build a framework of understanding of often quite opposing memories, leading to potential co-ownerships of memories. In this context, pluralities and singularities appear in a new light and the interaction of contacts and interests (that networks enhance) will define an effective framework for spreading trust and empathy across mental and physical borders.

In this way, through networking and mobility, different levels of métissages may take place, generating a number of implications, from social to economic and cultural dimensions. The web of relationships that will be established has so far proved to be capable of reinforcing cooperation in the future, producing ideas for harmonising differentiated societies, and ultimately promoting a shared, European sense of belonging.

Indeed, networking and mobility are not a peculiar 'invention' of EU institutions. European history has developed multi-layered networks over the centuries. Diasporic populations, travellers, explorers, intellectuals, artists,

7 Compare Jennifer Streeter, Networking in academia, in Емво Reports, Nov. 2014, 15 (11), pp. 1109-1112, available at https://www.ncbi.nlm.nih.gov/pmc/articles/PMC4253483 and the conference report of Marta Zampa, et al., 'What's in it for us?' Six dyadic networking strategies in academia, in Studies in Communication Sciences, 2015, 1 (15), pp. 158-16o. 
merchants, and migrants (from Jews to Germans, from Roma to Greeks, from Armenians to Italians, just to mention a few examples) repeatedly and severely marked the reshaping of European societies, strengthening their métissages in a plurality of forms. The circulation of ideas, the expansion of trade, and the development of transportation networks (from canal networks to railways on up to low-cost flights in more recent times) have powerfully contributed to reinforcing the process of cross-national fertilisation.

True, educational policies, promoted both by nationalism as ideology (despite the heterogeneity of its interpretations) and the nation-state building praxis since the French revolution, have systematically undermined the role of transnational networks and mobility within Europe. Concentrating their efforts on convincing people of their own 'uniqueness and homogeneity' in language, culture, history, and the arts, the national political cultures (however perceived) have transformed the humanities, and social and cultural studies into authoritative vectors of group identification, into tools for measuring loyalties, and into forms of legally and socially bound in-out relationships. Their separation from other disciplines has been applied according to the idea that the natural sciences in particular are the most reliable, trustworthy, and 'neutral'. Prominent scholars, like Gellner (1984) or Anderson (1991), have extensively analysed these phenomena and the role of the 'clergy of the nation' ascribed to the humanities only.

For at least two centuries the national political culture promoted educational systems by disregarding the extent and itineraries through which these métissages have been linking Europe. As a result, it has deeply affected the perception of 'otherness'. Therefore, conflicting narratives were nurtured and alternative memories constructed, while avoiding confusing effects with exact disciplines, that are allegedly considered to be not 'contaminated' by political ideologies (Cohen, 2001).

Instead, the EU integration framework offers an unprecedented space for contesting these opposing national narratives. Potentially, it will help in reconsidering the legacy of European knowledge as being the result of intense and multi-layered interactions. These stem from diasporic experiences, mobility, mutual contacts, and métissages, that is, factors that pave the way to a post-nation state cultural understanding. Therefore, the development of EU integration may generate a constructive context for building confidence and empathy across borders, making transnational cooperation, interdisciplinarity, and the use of multilingualism routine. For all these reasons, the founding fathers of the EU believed that this approach would better guarantee peace and development, as well as a more effective competitiveness for EU member states on the global level. 
Applying networking, interdisciplinarity, and mobility as working methods to higher educational institutions is not only consistent with such a rationale but also challenges the existing system of teaching. In this way, the internationalisation of universities takes on a new appearance, since it goes far beyond the international dissemination of scientific discoveries or the 'traditional' knowledge of other cultures on the basis of national interpretative criteria. By overcoming those current obsolescent approaches to knowledge, which are inadequate in the face of globalisation, the 'new' internationalisation encourages - through intense exchanges - a métis education, a transnational syncretism in terms of knowledge and lifestyles, as well as a nomadism of relationships, which are generating a new European culture, juxtaposed to the national ones.

Universities (as well as school systems) may represent a vibrant lever in this process of change, although not always aware of it, or willing to implement it, even when they are allowed to do so. Networking, mobility, and the Bologna process spread powerfully when the implementation of the Schengen treaty, the EU enlargement eastward, and low-cost flights converged. Under these circumstances, the time-space compression accelerated by IT connections was simultaneously the cause and the consequence of wide national shocks. I have stressed in other papers that the Schengen treaty is a revolutionary agreement, since it challenges one of the key pillars of Westphalian state sovereignty, that is, state control over a fixed population (Bianchini, 2015). Moreover, EU enlargement since 2004 and the intense low-cost flow of people have made visible the effects of a growing circulation of citizens. This freedom of movement within the Schengen area is a consistent implementation of one of the four freedoms of the EU.

In other words, a new educational policy is precipitating the gradual liquefaction (Bauman, 2000) of the existing learning process, which has remained trapped under national criteria restrictions for a long time. The mechanisms of mobility, networking, and exams/diploma compatibilities are creating radically new learning contexts. Multinational classes are growing in number and, even when this is not the case, faculty mobility is encouraging a cultural nomadism of students and the staff. Multilingualism is becoming a vital skill for communication between teachers and students, among students, and between teachers and staff for accomplishing administrative needs. This process is challenging the language homogenisation that characterised higher educational institutions until the fall of the Berlin wall.

Since then, a twofold language process has taken place. On the one hand, multilingualism has been encouraged by the $\mathrm{EU}$ as a prerequisite for participating in communitarian institutions, in training and educational programmes, as well as a fact stemming from the multinational peculiarity of classes. On the 
other hand, English has begun to play a predominant role in a number of international teaching programmes.

This development came with EU enlargement eastward, when the traditional two-sided relationship was replaced by multiple cooperation. Indeed, the process accelerated at the turn of the millennium when the EU was still only made up of a few member states and the Cold War was over. However, in the case of bilateral agreements between universities, leading for example to co-tutelles in $\mathrm{PhD}$ programmes or to double diplomas on specific disciplines aimed at enhancing the mutual exchange of knowledge, languages other than English are being used even today in the implementation of learning activities.

Nevertheless, a new phenomenon has emerged with the spread of English as the lingua franca in EU universities' international programmes. It is about the materialisation of a sort of 'EU or communitarian English', which is structurally different from the language spoken in the United Kingdom, mainly because it is a vehicle of communication for non-mother tongue individuals and, to a certain extent, because influenced by the communitarian terminology in use in Brussels, then disseminated in the member states. Because of these characteristics, the 'EU or communitarian English' is a language without literature, without poetry, therefore without the emotional sphere that marks national languages. In short, it is a product incompatible with any primordialist vision of a political society, far beyond the hopes and the dreams of Herder, Fichte, and the activists of anti-enlightened romantic nationalism.

As is well known, the identification of a nation with a language and its literature is rooted both in the ethnic and civic understanding of the nation, despite their own differences in approaches. It is enough to cite Mazzini or Wilson for confirmation that the literary language has been considered a benchmark of a nation, despite the tangible difficulty in defining what a language is. In any case, and consistent with this belief, the standardisation of national languages has been imposed by nation-state governments for amalgamation needs, marking the educational system in-depth, from primary schools to universities for at least two centuries.

Currently, however, the internationalisation of European universities is promoting a societal transformation of cultural elites, following a trajectory open to new frontiers in human relations. Determined by the multilingual education of mobile young generations, in a context where 'communitarian (not literary) English' is playing a predominant role anyhow, cultural nomadism is crucially contributing to the deconstruction of previous achievements in terms of social identification of a group. Consistent with an increasingly interdependent world, with the requirements of transnational markets and corporations, with the process of globalisation, the internationalisation of higher education in 
Europe - based on mobility, networking, diploma compatibilities, multilinguism, and communitarian English - is generating a transnational European élite acquainted with operating in contexts marked by diversities, heterogeneity, and a plurality of narratives.

This does not imply the end of literary English or national literary languages. Their construction in fact never eradicated pre-existing vernacular literatures anyway, which are still alive in poetry, movies, songs, and theatrical performances. Simply, there is little basis even to imagine such a cultural decline in the foreseeable future. On the contrary, 'not literary' English is becoming an additional achievement for transnational European culture. The success of its use across borders lies in juxtaposing it with current national languages and literatures, enhancing the potential produced by facilitated exchanges.

Moreover, the EU multi-language strategy (with English as a 'working language') is not the unique tool aimed at breeding new transnational elites. A crucial role will be increasingly played by curricula cooperation and the transnational awarding of diplomas, especially when combined with the mobility of students, teachers, and staff. This convergence of internationalising actions in the implementation of degree programmes will have a potent impact on both nation-state fusion and the awareness that identities are multiple, rather than 'unique and distinct' for each people.

Actually, the relationship between nation-state and national identity is intimately connected, like two sides of the same coin. The whole process of nation-state building has been promoted and carried out in Europe on the assumption that one dominant (and homogenising) identity is the strengthening factor of the collective sense of belonging, supposedly based on one language, one territory, one culture, one common history, a direct/mutual recognition between ruled and rulers, a shared economic system of interests, etc.

By contrast, universities' joint programmes generate a radically new educational environment. By attracting students and a faculty from different countries, by developing multiple forms of mobility, and awarding double, multiple or joint diplomas, a set of transversal skills flows in the teaching arrangement. As a result, disciplinary in-depth learning takes place in a context where students and scholars meet in a greater familiarity of otherness. Their interaction creates the best conditions for establishing a mutual knowledge, which involves habits, lifestyles, and an exchange of information about the variety of their countries of origin. In this way, trust is enhanced, empathy promoted, and diversities accepted as a norm, rather than a menace.

Consequently, the fluidity of the relationships that are produced goes far beyond the limits of the nation-state political culture, where neighbours are often seen as enemies or potential enemies, and diversities a factor of 'cultural 
contamination', which threatens the identity of the group. Instead, this fluidity is a great investment for peace and security, since studying and working together for two or more years increases the social permeability of the people involved and strengthens their networking capabilities. Cross-cultural adaptability skills and cross-disciplinary integration are, in fact, crucially relevant for young generations that are prospectively expected to act in a globalised world. In addition, the friendship relationships that they are able to establish meanwhile comprise an additional investment in terms of transnational networks that may prospectively operate in a number of fields, from business to politics, from arts to sciences.

\section{Internationalisation of Universities, Social Fluidity, and Resistance to Change}

Ulrich Beck focused his thoughts on the need to build a cosmopolitan Europe (Beck \& Grande, 2014). In fact, the strategies so far implemented in order to encourage the internationalisation of universities' curricula, mobility, research, and networking comprise a vital opportunity to establish a transnational society, based on interdisciplinary knowledge, which is simultaneously a pivotal lever for EU cosmopolitanism.

This prospective education is strictly connected with the scholarly development of research networks: the knowledge thus produced generates additional effects, beyond the universities' campuses in different social contexts. With the mobility of students, scholars, and staff, a plurality of bridges is established not only within the EU but also, broadly speaking, with all the countries involved at least in the EHEA. Studying and/or researching together encourages the preservation of dialogue and friendship, even in historical contexts where bilateral relations between states are contentious.

The involvement, for example, of the Russian federation in the EHEA is extremely important. Underestimating its desire for cooperation at the scholarly level by reducing funds or diluting the participation of Russian higher institutions in EU programmes as a consequence of mutual economic and political sanctions during a contingent political dispute is not only meaningless but may also lead to unpredictable negative consequences. Recent cultural and educational decisions of the European Commission are not encouraging in this regard. Luckily, however, not all doors were closed and cooperation with Russian universities has remained not only desirable but also possible.

In addition, mobility produces additional effects on the surroundings of the university campuses since local population and local economic activities have 
to cope with the needs and demands of a melting-pot- and highly educated society, whose aspirations include the respect of different religious prescriptions, food requirements, communication languages, wide internet access, entertainment, etc. As a result, the life of local communities faces new transformations and, in this respect, a broader 'educational dimension' stems from international programmes. Leaving classrooms, meeting local populations, and transferring knowledge to social and economic environments powerfully contribute toward reducing the still widespread negative perceptions of 'otherness' by assigning positive values to the movements of people and cultural syncretism. In other words, the internationalisation of university programmes can generate inclusive social feelings.

Recently, as a consequence of the major flow of migrants and asylum seekers from Africa and the Near East, the internationalisation of universities has manifested a new potential. That is, it has helped inclusiveness by offering opportunity to study to young people, while encouraging the local population to see the phenomenon with a different eye than that of racism, xenophobia, antisemitism, and anti-Islamic fears. Moreover, the presence of a growing community of students who are from mixed marriages or second-generation migrants, and possess multilingual skills can bridge the gap between the local and the global, making métissages and neo-nomadism gradually accepted.

Admittedly, governments, political parties, and social movements do not always welcome this challenge. Some of them, not necessarily right-wing oriented, like to appeal to emotions in order to attract consensus or mobilise voters to support them. Very often, when radical transformations are taking place, a sense of anxiety and reticence spreads within the society. This 'vulnerability' generates fear. Fear, in turn, encourages the rejection of changes among individuals; as a result, under these circumstances, sectors of public opinion fall into the trap of racism, xenophobia, antisemitism, and ethnic cleansing demands under the presumption that they are effective tools to restore group solidarity and the sense of security of the community (or nation). These phenomena are well known; they have been extensively studied and explain very well as the reason why wars occurred in Yugoslavia, Moldavia, and the Caucasus. In recent times, they shed light on what the sources are that incite racist waves in the EU member states, particularly the old ones, from Italy to the United Kingdom, from Denmark to Finland. Similar feelings are at the origin of the statements expressed by the leaderships of the 'Visegrad four' and the Baltic countries against the quota distribution of migrants and asylum seekers.

By contrast, the internationalisation of the universities represents an opportunity to promote an opposite cultural approach in terms of public engagement, educational skills, and socialisation. 
At the same time, however, the reform of higher education is still under the constraints of EU member states legislation, their national political cultures, and systems. Additional limitations are produced by neoliberal ideology, business approaches, and the way disciplines are studied, particularly the humanities and social sciences, as they traditionally define the civic education of new generations. Not surprisingly, they are often excluded from the hard science curricula. As a result, the technical education of students is not complemented by an understanding of the environment where they are expected to work. ${ }^{8}$

In a nutshell, a coherent implementation of university internationalisation is obstructed by a number of factors, which are generated partially by the powerful opposition of administrative bodies and partially by hostility against intercultural relations. Both phenomena are not only a mental product but also a consequence of the rooted polarisation between the global and the local.

Notwithstanding public statements and commitments, in particular those agreed and signed at the EHEA Ministerial Conference of Bucharest of April 26-27, 2012, little has been achieved since. Lots of words have flowed in support of academic and professional recognition, learning mobility, international openness, European qualification frameworks, and interdisciplinarity. Furthermore, 47 Ministers responsible for higher education in the European Higher Education Area concurred in encouraging higher education institutions to further develop joint programmes and degrees as part of a wider EHEA approach. We will examine national rules and practices relating to joint programmes and degrees as a way to dismantle obstacles to cooperation and mobility embedded in national contexts. ${ }^{9}$

The subsequent Conference of Yerevan, convened on May 14-15, 2015, recognised the negative impact of the bureaucratic approach on the common educational area and promised 'to give new impetus to the cooperation'. The signatory ministries made the commitment to review national legislation, remove obstacles to prior learning, and, therefore, facilitate the access to higher education programmes. In addition, they adopted special measures for joint

8 However, the exclusivist approached to curricula is increasingly contested. For example, the Colorado School of Mines has introduced studies in foreign languages, history, music, literature, and public affairs in the belief that 'Mines is not all about science and technology'. The Council of Europe in 2016 produced an important document: 'Competences for Democratic Culture. Living together as equals in culturally diverse democratic societies', where the inclusion of social sciences and humanities in hard sciences curricula is strongly recommended. See https://rm.coe.int/168o6ccco7.

9 http://www.ehea.info. 
degree programmes, stating that, if an agency is carrying out an evaluation of accreditation of the entire joint programme, 'the result is to be accepted in all EHEA countries'. ${ }^{10}$ How much of these assertions will be implemented remains to be seen. Potentially, however, they are an important step forward in overcoming the limitations encoded in most national legislation, which is still inadequate for facing the challenges of joint programmes and degrees, making the process of harmonisation slow to develop. Persistent national requirements, often mutually conflicting, make curriculum design and programme management a problematic exercise, if not a hazard.

In Italy, for example, obsolete 'tables of the classes of BA or MA programmes' cannot seriously be applied to international programmes and even less so 'imposed' on partners, particularly in cases like Austria, whose accreditation process implies that all partners offer at home a number of courses with the same learning outcomes and similar syllabi. Moreover, the accreditation process in Italy is valid for only one year, and every year a systematic submission of paperwork and a strict respect of quantitative criteria (that often change) prior to the beginning of lectures are required. On the contrary, in Lithuania the accreditation process, which is to be reformed soon, begins when the programme is under way, and only after a long qualitative process, led by an international commission, is accreditation awarded for a maximum of 6 years. Under these circumstances, the rules for adapting or modifying teaching plans during the implementation of the programme are often mutually conflicting and, if amendments to programme regulations are not carefully studied, adjustments may lead to an undesirable loss of accreditation in one of the partner countries.

Similarly, the list of career opportunities is recognised differently; it may happen that some professional profiles, which are normally included in the prospective educational goals of the programme in a partner country, are rejected in another one.

Additional difficulties revolve around the willingness of scholars to teach in a language other than their mother tongue. Basically, older generations are more reluctant than the younger ones. Moreover, some universities encompass this commitment within the regular obligations of the teacher. Others, instead, offer an economic incentive, whose amount varies considerably according to

10 See the European Approach for Quality Assurance of Joint Programmes, which was draft in October 2014 and then approved by EHEA Ministers in May 2015 during the Yerevan Conference. The document is available at the following address: https://www.eqar.eu/ fileadmin/documents/bologna/o2_European_Approach_QA_of_Joint_Programmes_v1_o .pdf. 
the circumstances. As a result, this behaviour becomes an issue when joint programmes need to be established between universities that apply different policies in this regard.

Therefore, carrying out a joint programme depends to a large extent on the degree of adaptability of the universities, which in turn rests on the individual willingness of the partners and scholars, on the level of flexibility of the administrative personnel, on the ability of the university officials to interact with the ministry and sometimes even to influence the interpretation of rules.

\section{7}

\section{Conclusion}

At the beginning of this article, I reported on the results achieved by the European human capital strategy. Erasmus mobility is still one of the most relevant success factors. I went on to elaborate on the political-cultural impact of this EU operation, which led to the establishment of EHEA, joint programmes and degrees, networking research teams, and so on.

By contrast, but not surprisingly, in the midst of the European crisis of governance, while facing asylum seekers and migration flow, the Slovak Presidency of the EU suggested in November 2016 to cut $50 \%$ of the Erasmus Programme budget for the years 2017-2020, down from the $€ 200$ million proposed by the EU Commission to $€ 100$ million.

The desire to annihilate such a successful programme patently stems from the fear that nationalist elites might be replaced, prospectively, by cosmopolitan, integrated, transnational, and nomadic European elites, which are educated through mobility, networking, and interdisciplinarity. Manipulating unscrupulously the unsettled issue of the migrant distribution across the EU and merging it with the fear of recent terrorist attacks, the Slovak proposal - albeit temporarily rejected - is a powerful indicator that EU integration is far from being consolidated.

Furthermore, Slovakia is not alone in this behaviour. For example, the Italian government has considered the possibility of establishing a threshold for the mobility expenses of all public administrations. Since state universities are considered public administration after the 2010 university reform, this proposal, if implemented, will affect the options of professors in spending the miserable amount they individually receive every year for their research activities. Treating, in fact, the Italian universities in the same way as the post offices, the aim of the state's policy is to obstruct one of the key international activities of academic researchers. Simultaneously, the newly established accreditation agency pretends to assess quantitatively their research production, by 
influencing salary awards and their eligibility in the national commissions for career advancements (regardless of their disciplines expertise).

Under these circumstances, it is evident that the internationalisation of the universities (as well as their autonomy) is seriously threatened. Reluctance to make the international activities of the higher institutions work is intensifying both within ministries and the administration of the same universities.

Furthermore, the legal fragility of the EU framework for university convergence is acutely being challenged. Despite magniloquent statements and some crucial cornerstones represented by the Erasmus Programme, the Bologna process, networking, and interdisciplinarity as methodologies, the EU still lacks a set of norms regulating the transnational joint structure of programmes, their accreditation, and quality assurance strategies. Leaving these tasks to the negotiating capacity of the member states, which are politically reluctant, administratively inflexible or, sometimes, just slow in harmonising their higher education policies has made the implementation and the management of joint programmes a deeply frustrating exercise and, in some cases, nearly 'mission impossible'. Under the new circumstances of the populist drift emphasised by Brexit, which was basically produced by a rejection of people mobility although not necessarily directed against the academic world, the delay in the harmonisation of university policies may generate a wide educational failure, able to affect negatively the aforementioned cornerstones. The collapse of the integrative sentiment within the EU has strengthened the belief that the centralisation of powers and the homogenisation of rules, according to national and local attitudes, are the most effective ways to guarantee control over education. Attempts to design regulations that return international programmes to national or even (local) university rules are prospectively increasing the parochialism of educational programmes. Instead of recognising the wealth stemming from multiple transnational cooperation, which requires negotiation with partners and administrative flexibility according to the needs of each programme, the trend is to homologate what cannot (and should not) be homologated.

Subsequently, the fear of flexibility is not only a peculiarity of governments. It is crucially embodied in public administrations, including those of universities with their own political presidia. This is not yet a generalised behaviour, but it is a trend: a growing trend. The prospective implications of this behaviour are easy to understand compared to the quality of teaching activities and the international education of young generations. Actually, the international education risks are fading gradually.

An additional detrimental factor that may affect the transformative role of international education is strictly connected to the increasing gap between the 
global elite (whose education is still in progress) and the persistence of local, parochial understandings of reality. This aspect is connected to the reasons why national governments have slowed down the development of international strategies of education. In fact, as is said, joint programmes (in their own wide variety of forms) are training a mobile, multilingual, métis, neo-nomadic, and transnational elite. Its inner closeness is reinforced by its ability to handle both new communication systems and the new geography of connections that the Internet and low-cost flights are radically transforming. Their contribution to space-time compression annihilates distances and borders, making urban centres and far away cities from rural areas closer. In this context, part of the population is going to be trained in order to face the challenges of integration and globalisation, while another part, often monolingual and sedentary, remains excluded. This cultural disparity is already polarizing the global and the local understandings of real life. Consequences are visible not only and not so much between generations, but mostly between differently educated people and/or between people who had divergent opportunities to access knowledge and a career.

It is among those lacking adequate tools to interpret social changes that emotional reactions against interculturalism, or phenomena like racism and xenophobia, have greater chances of being nurtured. In other words, an essential human 'reserve' is mentally disposed to follow exclusive political strategies, even if they are unable to govern the fluidity of the changes of our world. Paradoxically, the mix of feelings of rejection and intolerance, insecurity and uncertainty that characterise such guidance is not only culturally fragile but has a transnational character. It crosses borders, can easily be identified in a plurality of countries, and recently has been seeking some sort of convergence even within the European Parliament, despite their demands for strict national cohesion, the emphasis on territory and sovereignty, and the critiques of integration and globalisation. This polarisation is very dangerous because it paves the way for radical clashes, to severe cultural incompatibility within European societies, with unpredictable repercussions for the EU future.

This is the context where universities are expected to play an innovative role, far beyond any attempt at restricting their training mission within the limits of vocational or national schemes. In other words, they have a tremendous task ahead. They need to enhance the education of a new elite, spread critical thinking so it extends beyond classrooms and influences society by establishing a more dynamic relationship with the school system.

The world is changing and higher educational institutions cannot relinquish their responsibilities and raison d'être under these circumstances. Joint 
programmes currently represent the most intense opportunity for re-launching a leading role for the universities, producing synergies across the borders, not only in the interest of EU integration, but more broadly, in order to expand knowledge, trust, and empathy among people. The aftermath of these actions, either teaching or research network findings are to be shared with a broader community. In this context the relationship between universities and schools may prospectively play a crucial role.

We are living in a global, increasingly comprehensive society. New generations need tools to facilitate their job in intercultural environments, multi-skill acquisitions, and a strong interdisciplinary sensitivity. It is increasingly inadequate to contain knowledge within separate boxes, despite the resistance of academia, which still concentrates its efforts on protecting the priority of disciplines in the identification of teaching programmes, $\mathrm{PhD}$ studies, even in the selection of scholars. On the contrary, the same flow that is eroding borders and nations is melting disciplinary rigidity. Any act of knowledge, decision, information, analysis, reconstruction of events, etc., requires a comprehensive approach, able to grasp the complexity of implications that, at different levels, may affect our increasingly multifaceted societies. Consequently, a leading elite is expected to develop an interdisciplinary methodology and an interdisciplinary sensitivity, because educated accordingly. At the same time, in order to soften the global/local gap mentioned above, transnational educational systems should promote interdisciplinary approaches, plurality of angles, and subject contents both in LLL programmes, in the schools, and in the media.

To conclude, universities do control a decisive lever for EU integration, peace, trust, and empathy in our societies. They have an obvious social engagement in terms of building knowledge and matching the needs of the times. Joint programmes are the next, crucial step to be implemented, in combination with networking, mobility, interdisciplinarity, research, multilinguism, and transversal skills.

Despite resistance at the national and local level, the academic world cannot spend time remembering a supposed 'golden age' of early national university organisation. On the contrary, it is expected to face the challenges of globalisation and world transformation. It is expected to show the courage of innovation, to break down obsolescent and centralised rules, expand flexibility in the forms and quality of teaching, produce new synergies for society, and cope with the reorganisation of human life and its relationships according to the quick changes imposed by space-time compression. Nation-state fusion is, in this context, unavoidable. It is for governments and public administrations to decide whether it is more fruitful to govern the change or to resist it. For their own nature as centres for producing knowledge, it is a must for 
universities to confront the new and act transnationally. Otherwise, they lose their role and raison d'être.

\section{References}

Altbach, P., Reisberg, L., \& Rumbley, L. (2009). Trends in Global Higher Education: Tracking an Academic Revolution. Paris, UNESCO.

Anderson, B. (1991). Imagined Communities. London, Verso.

Bauman, Z. (2000). Liquid Modernity. Cambridge, Polity press.

Beck, U., \& Grande, E. (2014). Cosmopolitan Europe. Cambridge: Polity Press.

Bhola, H.S. (1997). Adult education policy projections in the Delors report. Prospects, 27 (2), 207-222.

Bianchini S. (2015). Yugoslav and EU decline. The dynamics of dissolution and sovereignty reframed, In Jensen, J., \& Miszlivetz, F. (eds.), Reframing Europe's Future. Challenges and Failures of the European Construction, Abingdon-New York, Routledge, $160-178$.

Braidotti, R. (2011). Nomadic Theory. The Portable Rosi Braidotti. New York, Columbia University Press.

Brandenburg U., \& De Wit, H. (2011). The end of internationalisation. International Higher Education, 62, 15-17.

Cohen, B.R. (2001). Science and humanities, across two cultures and into science studies. Endeavour, 25 (1), 8-12.

De Wit, H. (ed.) (2013). An Introduction to The Higher Education Internationalisation. Milan, Vita e Pensiero.

Etkowitz, H. (1993). Innovation in innovation: The triple helix of university-industrygovernment relations. Social Science Information, 42, 293-338.

Etkowitz, H., \& Leydesdorff, L. (1995). The triple helix: university - industry government relations: A laboratory for knowledge-based economic development. EASST Review, 14, 14-19.

Gellner, E. (1984). Nations and Nationalisms. Oxford, Basil Blackwell.

Gerschenkron, A. (1962). Economic Backwardness in Historical Perspective. Cambridge, Harvard University Press.

Knight, J. (2008). Higher Education in Turmoil. The Changing World of Internationalisation. Rotterdam, Taipei, Sense Publishers.

Maringa, F., \& Foskett, N. (2010) (eds.), Globalisation and Internationalisation of Higher Education. Theoretical, Strategic and Management Perspectives. London, Bloomsbury Publishing.

Ranga, M., \& Etkowitz, H. (2013). Triple helix systems: An analytical framework for innovation policy and practice in the knowledge society. Industry and Higher Education, (4), 237-262. 
Scott, P. (2005). The Global Dimension: internationalising higher education, In Khemj, B., \& De Wit, H. (eds.). Internationalisation in Higher Education: European Responses to the Global Perspective. Amsterdam, European Association for International Education and the European Higher Education Society (EAIR).

Streeter, J. (2014). Networking in academia, in EMBO Reports, November 2014, 15 (11), 1109-1112 retrieved from https://www.ncbi.nlm.nih.gov/pmc/articles/PMC4253483.

Szyszlo, P. (2016). Internationalisation strategies for the global knowledge society. $\mathrm{Ca}$ nadian Bureau for International Education (CBIE)-Bureau canadien de l'éducation internationale (BCEI), CBIE PhD Research Series.

Teichler, U. (2004). The changing debate on internationalisation of higher education. Higher Education, 48, 5-26.

UNESCO.(1996). Learning:The Treasure Within. Retrieved from https://unesdoc.unesco .org/ark:/48223/pfoooo10959o.

Zweig, S. (2014). Tempo e mondo. Solo gli uomini muoiono, mai le idee. Conferenze e saggi 1914-1940. Prato, Piano. B. (eds.).

\section{Further Readings}

Council of Europe. (2016). Competences for Democratic Culture. Living Together as Equals in Culturally Diverse Democratic Societies, Strasburg. Retrieved from https:// rm.coe.int $/ 16806 \mathrm{ccc0} 7$.

Delors Commission. (1996). Learning: The Treasure Within, Delors Commission Report to UNESCO of the International Commission on Education for the 21st century. Paris, UNESCO.

European Commission. (2014). Erasmus Impact Study - Effects of Mobility on the Skills and Employability of Students and the Internationalisation of Higher Education Institutions. Retrieved from http://www.eubusiness.com/topics/education/ erasmus-impact.

Generation Europe Foundation. (2014). Erasmus voting Assessment Project Final Report. Retrieved from http://issuu.com/generationeurope/docs/evaproject_final_ report_fordistribu/1?e=1430744/9429338, p. 35 .

Labrie, N., Amati, R., Camerini, A.L., Zampa, M., \& Zanini, C. (2015). What's in it for us? Six dyadic networking strategies in academia. Studies in Communication Sciences, $15(1), 15^{8-160 .}$

Sobhi, T., \& Cougoureux, M. (2013). Revisiting Learning: The Treasure Within. Assessing the Influence of the 1996 Delors Report. Paris, UNESCO.

UNESCO. (2015). International Bibliographic Database on Higher Education. Paris, The International Association of Universities.

UNESCO. (2005). Towards Knowledge Societies, Paris, UNESCO. 